\title{
Sob a Batuta de Horácio: Metros Horacianos em Português, Alemão e Inglês
}

\author{
Érico Nogueira \\ Federal University of São Paulo
}

Gostaria de começar este estudo sobre certa fortuna de Horácio - ou, mais especificamente, sobre como Horácio enriqueceu o repertório métrico do latim e como o seu precedente foi seguido por diferentes poetas em diferentes línguas, inclusive brasileiros escrevendo hoje em português refletindo sobre um passo de Paul Veyne no já clássico Como se Escreve a História (1971). A certa altura do ensaio, fazendo o panegírico de Michel Foucault, Veyne afirma que sua principal contribuição para a teoria e para a escrita da história foi a ênfase na diferença - isto é, a opção de Foucault por concentrar-se nas rupturas, na descontinuidade, na heterogeneidade, em suma, radical entre o presente do escritor e o passado que se escreve. Lembrando um adágio conhecido - tanto que é quase um clichê -, "O passado é um país estrangeiro".

Bem, a esse conhecido e, digamos, clicheesco adágio, contudo, eu responderia com estoutro, possivelmente mais adequado a um texto como este: Est modus in rebus - ou, como diz o vulgo, "Nem tanto ao mar, nem tanto à terra". Pois a 
constatação - óbvia, de resto - de que o passado é distinto do presente não pode, ou pelo menos não deve, nos cegar para a obviedade oposta, e por isso mesmo complementar, de que também são semelhantes; semelhantemente diferentes ou diferentemente semelhantes entre si, portanto, com o perdão do oximoro.

Dessa maneira, a despeito das previsíveis torções e distorções que sofreu e vem sofrendo, é lícito que evoque a figura tão romana, em geral, e em particular tão augustana, do poeta doctus. Surgido, ou pelo menos celebrizado, na Alexandria dos Ptolomeus, o ao mesmo tempo bibliotecário e poeta, teórico e prático, juiz de poesia e fabricante de poemas, enfim, é - com todas as mudanças por que passou, repito - uma constante ou tipo ideal na história da literatura do Ocidente, que, se se encarna à perfeição num Horácio, num Petrarca ou mesmo num Eliot, aparece também, aqui e ali, desmilinguido e desfigurado.

Decadências à parte, o facto é que a especialização dos domínios ou esferas do saber em que Max Weber enxergava o próprio núcleo da modernidade levou boa parte dos poetas contemporâneos, nas Américas e na Europa, a refugiar-se na academia, e, como poetas-pesquisadores ou poetas-docentes, escrever uma poesia esotérica que segue de perto ou de longe alguns dos princípios teóricos de sua confraria particular-precisamente o meu caso. Ora, lembrando nossa ideia inicial, nem o fenômeno é de todo novo, nem deixa de ter lá a sua novidade, evidentemente: pois, se, por exemplo, as muitas "querelas de antigos e modernos" que se têm repetido ao longo da história da poesia mais refinada, subtil e erudita são prova mais que contundente de especialização extrema e de um como fechamento de poetas-especialistas em grupelhos diversos e via de regra opostos, a relação que esses grupelhos, do Romantismo em diante, têm mantido com a tradição, e a noção mesma de tradição e de cânone, parece que se tornaram mais problemáticas, questionáveis, arbitrárias até. Descrita nesses termos, soa como puro incômodo, 
mas não se enganem - a situação pode ser bastante confortável. Nas palavras do poeta e bibliotecário Philip Larkin¹:

Não é nem de longe um exagero dizer que o poeta acedeu à feliz posição em que pode elogiar sua poesia no jornal e explicá-la na sala de aula, de maneira que o leitor se sente intimidado a abdicar do seu direito de consumidor - qual seja, o de dizer "Este eu não quero: me traga outro".

Enfim: toda essa conversa sobre relações entre passado e presente, e a deselegância, ademais, de "Eu isso, eu aquilo", foi um desvio - ou um atalho - para chegar ao meu ponto: isto é, primeiro, que, o experimento de Horácio sendo ao mesmo tempo semelhante e diferente dos modernos que se lhe seguiram, como tal deve ser lido e considerado; segundo, que o espaço e o tempo do que direi sobre poetas de fora e de ontem é o Brasil de hoje, de maneira que o princípio e o fim do meu discurso arqué e telos - é a observação ou constatação pessoal, embora não restrita à minha pessoa, de que ao menos parte da poesia brasileira contemporânea original e traduzida pode descrever-se como classicizante, filoclássica ou algo do teor, e nela Horácio é mais que um nome: é um princípio de composição; e, terceiro, por fim, que, sem ser exclusivo de Horácio, mas transmitido sobretudo por ele aos classicismos posteriores ao seu, esse princípio compositivo não é outro que a celebérrima imitação.

Assim, proponho um itinerário que percorra todos os três momentos ou aspectos do meu ponto tríplice, em sentido, porém, inverso ao em que acabo de o apresentar - isto é, começando com breve reflexão sobre o conceito e a prática da imitação na poesia da Europa e das Américas, e passando, depois, exatamente nesta ordem, à caracterização de uma possível tendência classicizante na poesia brasileira contemporânea e à consideração, enfim, de umas inovações métricas de Horácio e de dois poetas modernos que lhe

Esta e todas as traduções referidas neste texto são de nossa autoria.

Larkin $(1983,81)$. 
seguiram o autorizado exemplo (no caso, Johann Heinrich Voss e Geoffrey Hill) - momento em que, tão detalhadamente quanto puder, discutirei questões técnicas como acentuação, cesuras e fins de verso em versos gregos, latinos, alemães e ingleses, claro está, mas também e sobretudo em sua tradução portuguesa, que procurarei justificar. Mãos à obra.

I.

Em instigante e eloquente trabalho apresentado ao Departamento de Letras Clássicas e Vernáculas da USP como tese de livre-docência - refiro-me a "Dos Gêneros da Poesia Antiga e sua Tradução em Português"- João Angelo Oliva Neto observa que o conceito grego de imitação, ao sair da Atenas de Platão e Aristóteles e aportar na Roma de Horácio, fez escala na Alexandria de Calímaco, onde o seu sentido primeiro se enriqueceu e se modificou: isto é, de imitação, principalmente, dos objetos, de ações humanas - de algo, em suma, que está no mundo, e que em última instância é extralinguístico ou extrapoético -, passou a ser também, e preponderantemente, imitação, vá lá,intrapoética ou intralinguística de paradigmas autorizados.

Bem, qual tenha sido a importância da teoria e da prática da imitação de modelos canônicos, em poesia, do arcaico Hesíodo ao neoclassicismo do século XVIII, todos sabemos e estamos cansados de saber - imitar era simplesmente o motor da fábrica poética, só isso, para usar metáfora industrial. Mas o que não sabemos assim tanto, e, se sabemos, olvidamos frequentemente, é que a ala ou seção literária da Revolução Francesa, a que soemos chamar Romantismo, se, por um lado, encareceu a originalidade, a singularidade, a em termos kantianos "saída do homem da menoridade que a si mesmo se inflige" ${ }^{3}$ e consequente libertação das autoridades que não

\footnotetext{
3 Kant $(1784,481)$.
} 
pudesse racionalmente justificar, por outro não cancelou, não baniu, não exterminou a antiga prática da imitação. Como ensina Rosado Fernandes em página exemplar que vale a pena aduzir integralmente:

Mímesis, imitatio, imitação, eis um termo cuja riqueza semântica passa despercebida ao leitor moderno, uma vez que desde há muito tempo o ato de imitar passou a ser conotado como reprodução ou cópia servil de um modelo. A própria moda intelectual da atualidade repudia qualquer imitação, pois todos pensam atingir certa originalidade e pensam que a originalidade, embora potencialmente ligada a modelos, a arquétipos, aparece como que flutuante e ligada ao artista que a criou. Daí a criatividade ser entendida como original, sem que jamais se macule com qualquer ideia de imitação. Cremos que esta noção romântica e recente, se atendermos à história do mundo, de originalidade, sempre existiu, só que existiu a paredes meias com a imitação, como processo em si, como forma de reproduzir artisticamente o real, ou como forma de aproveitar de modelos, para neles incluir algo de pessoal, inevitavelmente existente, quando provém de um artista criativo. Imitar significa, agora, para qualquer cultor das artes o mesmo que plagiar, significava contudo na Antiguidade e até o século XVIII, algo de diferente, de formalmente diferente, ainda que na essência tudo seja, antes e agora, profundamente o mesmo. Só o acidental mudou, como mudou a moda, como se alteraram os preceitos, que no mundo moderno parecem menos evidentes do que nos velhos cânones. Mudou a atitude, o que é significativo, mas não há dúvida de que os autores ou os artistas continuam a pertencer a escolas, continuam a escolher modelos - continuam a imitar, se a palavra e a noção, se o significante e o significado estivessem em uso, se os realistas ou os neorrealistas se reclamassem dos seus modelos, se os cultores do nouveau roman afirmassem a paternidade do seu discurso, se os que seguem cuidadosamente as estruturas narrativas de um James Joyce admitissem que claramente o imitam, sem que com isso o reproduzam e dele façam centões. Tudo isso passou; fala-se de "reescrita", de "intertextualidade", quando há um modelo evidente, como é o caso de Homero 
para o Ulysses de Joyce, ou de Horácio para o Ricardo Reis de Pessoa, mas já não se fala de imitação. Na Antiguidade não era assim, nos tempos antigos, se assim podemos dizer, também não. ${ }^{4}$

Sábias palavras, sem dúvida - quando mais não seja, porque denunciam o óbvio: isto é, e insistindo na metáfora fabril, que, se a imitação não é mais todo o motor da produção e do consumo de poemas, nunca deixou de integrar suas engrenagens... Vale dizer, em termos mais exatos, que, deixando embora de ser o mais importante e explícito (essa é a palavra) critério de composição e apreciação de poesia, nem por isso a imitação caducou ou prescreveu. Muito pelo contrário: escamoteada sob os pseudônimos de "reescrita", "intertextualidade", "alusão", "empréstimo", “diálogo", “influência”, etc. etc. etc. - o importante é um nome up-to-date -, a imitação, como no passado, original e criativa de modelos que, aí sim distintamente do passado, não estão estabelecidos nem dados de antemão, é expediente fulcral, nuclear, imprescindível, se não de todas, de muitas das obras que a Modernidade paradoxalmente vem considerando "clássicos modernos". Além das que Rosado Fernandes menciona, quem ignora que os autos medievais são o modelo do Fausto de Goethe ou que a Divina Comédia está na base de As Flores do Mal de Baudelaire, por exemplo, para citar apenas as inescapáveis? Acho que ninguém.

Sendo assim, o que mudou entre a antiga e a moderna prática da imitação foi, primeiro, a natureza do cânone: ontem mais rígido e restrito, hoje mais flexível e mais aberto; segundo, o carácter explícito e obrigatório da imitação mesma, e sua função, dir-se-ia, pedagógica e diretora, tanto para aspirantes a poeta como para poetas consumados: hoje imitar (refiro-me à atividade consciente) é opção, e isso talvez explique a técnica

Rosado Fernandes (1986, 11-12). 
sofrível e o paupérrimo cabedal de muitos poetas jovens... e não tão jovens. Vovô Horácio já dizia:

Cur ego, si nequeo ig $\mid$ noro|que, poeta salutor?

Ora, por que, se sou néscio | e ignaro, me chamam poeta?5

Finalmente, gostaria de terminar esta primeira parte do meu argumento com uma famosa passagem de Eliot, em que se distingue o poeta bom do ruim, o maior do menor, precisamente pela maneira de tomar emprestado, imitar, furtar o alheio e fazêlo seu. Ainda que não fosse esta a sua intenção, tais distinções testemunham a constância da imitação criativa, na história da poesia antiga e moderna, já que basicamente repetem e refundem o arquifamoso conselho do venusino no tocante à "matéria de domínio público" que se pretenda fazer "de direito privado"... - todos sabemos: Arte Poética 131-135. Será mera coincidência - sobretudo se se nota que Eliot, para quem a imitação deve ser original, é original ele próprio em relação ao conselho que imita? A mim me parece que não. Mas vamos ao texto:

Um dos testes mais seguros [da maturidade e da grandeza de um poeta] é a maneira como toma emprestado. Poetas imaturos imitam [i.e., copiam servilmente]; poetas maduros furtam [ou seja, criativamente remodelam]; maus poetas deformam o de que se apropriam, mas os bons o transformam em algo melhor ou pelo menos diferente. $\mathrm{O}$ bom poeta funde o que pilhou numa singular unidade de percepção em última instância diferente da origem; o mau o mistura com o que não tem nenhuma coesão. [Finalmente,] o bom poeta costuma tomar emprestado a autores distantes no tempo, de língua estrangeira ou com interesses distintos dos seus. ${ }^{6}$

\footnotetext{
Hor., Ars 87.

$6 \quad$ Eliot $(1921,114)$.
} 
Retenhamos a ideia final - imitar (ou pilhar) autores longínquos no tempo, no espaço ou na poética mesma - e passemos adiante.

II.

A fim de identificar e descrever a parte filoclássica do todo mais ou menos heterogêneo chamado "poesia brasileira contemporânea", vou me valer de uma teoria - a dos polissistemas - que o estudioso israelense Itamar Even-Zohar vem desenvolvendo e aperfeiçoando desde a distante década de setenta, a partir de sugestões da dita linhagem dinâmica ou funcionalista do formalismo russo: principalmente Chklóvski, Tynianov e Ejxenbaum.

Em termos bastante resumidos - e simplificados -, trata-se de fazer justiça ao fator "tempo", considerando, a par e par dos sincrônicos, também os elementos diacrônicos, ao buscar-se uma descrição acurada das estruturas que integram e regulam o sistema literário (sempre plural: daí polissistema) num lugar e num momento precisos.

Assim, escapando de tudo o que é sociologismo rasteiro, Even-Zohar (1990) pôde enriquecer e expandir em muito o raio de ação do estruturalismo mais rigoroso e - por que não? - científico, granjeando-lhe a possibilidade, ou antes a necessidade, de correlacionar (a via aqui é de mão dupla) o polissistema literário, em geral, e em particular o poético que nos interessa, com outros polissistemas da cultura eventualmente em causa: o filosófico; o econômico-social; o político - por exemplo.

Mas fica a pergunta: Do sem-número de elementos passíveis de observar-se no domínio da literatura, quais seriam os axiais, ou, pelo menos, os mais aptos a compor um modelo teórico suficientemente amplo e exato desse domínio - um modelo, portanto, capaz de lhe mapear e detalhar o funcionamento interno, e as principais relações com contradomínios quaisquer? Ora, se a descrição que Jakobson pretende aplicável a toda comunicação 
verbal tem qualquer validade científica - fazer ciência em sentido forte: meta do formalismo russo que Even-Zohar atualiza e mantém -, nada mais racional do que adaptar essa descrição ao caso específico da comunicação literária, sendo esta, como é, uma instância particular da verbal pura e simples. Dito e feito: partindo de Jakobson, eis o modelo de Even-Zohar e as palavras com que o descreve:

$$
\begin{gathered}
\text { INSTITUIÇÃO [contexto] } \\
\text { REPERTÓRIO [código] }
\end{gathered}
$$

PRODUTOR [remetente]-------------[destinatário] CONSUMIDOR

$$
\begin{gathered}
\text { MERCADO [canal] } \\
\text { PRODUTO [mensagem] }
\end{gathered}
$$

\footnotetext{
Neste caso, um CONSUMIDOR pode "consumir" um PRODUTO fabricado por um PRODUTOR, mas, a fim de que o "produto" (por exemplo, o "texto") efetivamente se produza, é preciso haver um REPERTORIO comum, cujo emprego é determinado por alguma INSTITUIÇÃO. Também deve haver um MERCADO em que essa mercadoria circule. Não se pode descrever isoladamente o funcionamento desses fatores, e suas relações observáveis dão-se em todos os possíveis eixos desse esquema. ${ }^{7}$
}

Muito bem: se, pois, atribuindo um valor específico às variáveis acima, eu puder fornecer uma descrição minimamente satisfatória da que chamei tendência classicizante ou filoclássica na poesia brasileira contemporânea, ficam provadas e justificadas, primeiro, a eficácia de nosso modelo teórico, segundo, a existência mesma dessa tendência, se não incondicionalmente ou "em si", ao menos condicionada a um modelo teórico eficaz. Para tanto,

Even-Zohar (1990, 34). 
contudo, é preciso fazer umas observações preliminares, e definir mais exatamente nossos conceitos principais:

1) Tendência classicizante: procedimento ou traço mais ou menos comum a um grupo significativo de poetas, segundo o qual se apropriam da forma (técnicas, ritmos) e do fundo (motivos, tropos) da poesia latina e grega, em particular, e, em geral, da dos chamados classicismos e neoclassicismos subsequentes.

2) Imitação: em termos resumidos, a apropriação do fundo e da forma, que acabamos de mencionar; mais detalhadamente, a (no jargão de Even-Zohar) interferência de um repertório dito clássico em outro que, ou porque jovem, ou pobre, ou porque passa por alguma crise, se vê na contingência de firmar-se, enriquecer-se ou alterar-se exatamente mediante essa interferência - conceito que, pois, o de interferência, abarca a imitação propriamente dita (isto é, a preconizada nas antigas poéticas e retóricas), o furto de T. S. Eliot e a transcriação de Haroldo de Campos $\left(1992^{4}\right)$, por exemplo, e põe a poesia original e a traduzida como que em pé de igualdade.

3) A fatia filoclássica do bolo poético brasileiro contemporâneo: poemas originais expostos à interferência do legado clássico, e traduções poéticas desse legado.

Feito isso, partamos agora para a descrição efetiva. Diferentemente do que acontecia há trinta ou mesmo há vinte anos quiçá, o PRODUTO "poesia clássica original e traduzida em português” parece que está em voga, porquanto o evidente prestígio de que hoje gozam as traduções de Manuel Odorico Mendes, Carlos Alberto Nunes, Haroldo de Campos, Jaa Torrano, Trajano Vieira e João Angelo Oliva Neto, entre outras, - aliado, esse prestígio, ao da poesia original dos clas- 
sicizantes Alexei Bueno, Paulo Henriques Britto, Alberto da Cunha Melo, Bruno Tolentino e Gerardo Mello Mourão (a lista não é exaustiva) - é indício mais ou menos seguro, creio eu, de que esse produto circula no MERCADO e é procurado pelo CONSUMIDOR, a quem o PRODUTOR se remete. Sancionada por universidades, imprensa, academias de letras e galardões literários - por tudo, enfim, que integra a chamada INSTITUIÇÃO -, a fabricação de poesia classicizante, no Brasil de hoje, se caracteriza pelo uso de matéria clássica, claro, que é o traço mais saliente das empresas do jaez: o que, porém, não é um traço muito saliente delas, por seu turno, e a meu juízo distingue umas recentíssimas manifestações da tendência ora em pauta, é o uso da métrica latina e grega, que, ao lado de outros expedientes elocutórios, compõe, com a referida matéria, o grosso do REPERTÓRIO clássico ontem, hoje e sempre à disposição.

Ufa! - com isso de métrica chego ao terceiro aspecto e ao cerne deste texto, afinal, cujo título "Sob a Batuta de Horácio", fazendo do poeta compositor e regente, prometia uma consideração mais sistemática de como uns intérpretes seus, de lugares, períodos e línguas diversos, têm respondido a essa regência e executado sua música... Promessas à parte, a esta altura o meu circunlóquio se explica: pois a sala de concerto, por assim dizer, onde essa música é lida, tocada e ouvida não é outra que um novo desenvolvimento da tendência classicizante que acabo de caracterizar, o qual, numa palavra, consiste na aclimatação de metros latinos e gregos ao português. No caso da poesia traduzida, essa como última floração é representada principalmente pela reavaliação positiva de Carlos Alberto Nunes $^{8}$ e suas traduções da Ilíada, Odisseia e da Eneida - e, mais ou menos em sua órbita, pelo Píndaro de Leonardo Antunes (2012), o meu Teócrito (2012) e - voilà! - o Horácio lírico de Guilherme Gontijo Flores (2014), entre outros, todos três

Cf. Oliva Neto; Nogueira (2013). 
apresentados ao Departamento de Letras Clássicas e Vernáculas da USP como teses de doutoramento. Já no que toca à poesia original, me ocorrem por ora os ritmos hexamétricos de João Filho em A Dimensão Necessária (2014) e os milhares - sim, milhares - de hexâmetros vernáculos compostos à maneira de Klopstock pelo jovem e infelizmente inédito poeta brasilogermânico Gregório Barbosa Souza - além de meus próprios experimentos com o hexâmetro de Virgílio e com células métrico-rítmicas inspiradas em estrofes de Horácio encontráveis em Poesia Bovina (2014).

Bem: chega do que pode soar uma inconveniente apologia pro poetica mea e vamos logo (ou finalmente) ao que interessa.

\section{III.}

Escrito por um dos mais importantes e ativos protagonistas das relações entre romanos e gregos, o exórdio das Tusculanas testemunha uma espécie de "angústia da influência", digamos assim anacronicamente, e, conquanto teime em ostentar que não, trai um sub-reptício sentimento de inferioridade do conquistador romano, no tocante às letras e as artes gregas em geral. A história é manjada - e nas igualmente manjadas palavras de Horácio diz-se assim:

\footnotetext{
Graecia capta ferum | uictorem cepit et artis intulit agresti Latio.

Grécia, a cativa, o feroz | vencedor cativou - e as artes introduziu no agreste Lácio. ${ }^{9}$
}

Ora: se pudermos, então, partindo do mote de Cícero em sua formulação horaciana, glosar aqui a já mencionada teoria da interferência de polissistemas literários relativamente centrais sobre os ocasionalmente periféricos (que podem ser jovens,

Hor., Ep 2.1.156-7. 
pobres, estar em crise, ou todas as anteriores - é bom lembrar), abriremos um terreno mais ou menos seguro, me parece, sobre que construir nossas comparações entre Horácio, Johann Heinrich Voss, Geoffrey Hill e a novíssima voga filoclássica da poesia brasileira, haja vista que, como nos revela uma breve e compulsória relação de certas obras-chave e suas respectivas datas de publicação, tanto o sistema poético de Horácio em relação ao grego, quanto o de Voss comparado ao francês e ao inglês, e o brasileiro no tocante ao hispano-americano, ao norte-americano e ao europeu ocidental, se encontram sim, de uma maneira ou de outra, em situação de relativa inferioridade - raciocínio este, enfim, que, ao menos a julgar pelo incisivo $A$ Sinking Island, de Hugh Kenner, publicado em 1988, se aplica também ao antigo (e antiquado) sistema poético inglês - o de Hill - ao lado do americano, considerado pujante, diversificado e vivamente atual. (A omnipresença de Pound - e, mais que a dele, a de Eliot - na poesia e nos ensaios de Hill parece confirmar o juízo de Kenner.) Bem, vamos lá.

Considerando, pois, como disse, algumas obras-chave da poesia latina, alemã, inglesa e brasileira, e a relação que mantêm com modelos clássicos ou tradições concorrentes, noto uma semelhança entre o tempo de Horácio e o de Voss, por um lado, e, por outro, entre a Inglaterra e o Brasil atuais.

Com efeito, tanto os esforços de Horácio para aclimatar a lírica grega ao latim como as traduções horacianas de Voss precedem, em poucos anos, a publicação do maior monumento poético da respectiva língua, já que os primeiros três livros das Odes foram publicados em 23 a. C. e a Eneida de Virgílio pouco depois de 19 a. C., enquanto o primeiro volume das Obras de Quinto Horácio Flaco de Voss apareceu em 1806 e a primeira parte do Fausto de Goethe em 1808... Essas são as datas, esses são os factos; - ora, sem nem sugerir nem muito menos postular qualquer mecânica relação causal entre Horácio e Virgílio, Voss e Goethe, não me parece de todo descabido dizer que as 
mais altas realizações da poesia latina e da alemã se inserem em ambiente e situação bem mais amplos, de ativa apropriação, aclimatação, imitação do legado grego, no caso do latim, e, no do alemão, dos legados grego e latino, principalmente. Já quanto à semelhança da poesia que se vem fazendo na Inglaterra com a que no Brasil se vem fazendo hoje, observo primeiro que, tanto lá como cá, há quem julgue um poema classicizante como o auge e cúmulo dessa poesia, no século XX - refiro-me a "Four Quartets" de T. S. Eliot e "A Máquina do Mundo" de Carlos Drummond de Andrade; segundo, que, atingido esse cúmulo e auge entre os anos quarenta e cinquenta daquele século, seguiu-se-lhe um período de relativo declínio; e, terceiro e por último, que, a fim de remediar esse declínio relativo - isto é, um robusto polissistema em crise, no caso do inglês; e um polissistema em crise, pobre e jovem, no caso do brasileiro -, volta-se sempre e de novo e mais uma vez aos clássicos.

Dessa maneira, supondo seja possível tirar conclusões mais gerais dos exemplos demasiado particulares que acabamos de referir, eu diria que a imitação do legado clássico, tendencialmente e no mais das vezes - não se trata de uma "lei da história literária”, observe-se -, bem, a imitação ativa e criativa do legado clássico parece acompanhar, em muitas circunstâncias, seja o movimento ascendente, que leva e eleva uma tradição poética à plena realização - e nesse caso ela é uma força propulsora -, seja o movimento descendente, que dilapida e degrada a conseguida excelência - e aí ela é uma força de reação. O que de certa maneira parece corroborar a sentença de Kant - paradoxalmente, como o seu paradoxal século XVIII, o pai da mais radical modernidade, em matéria de ética e de metafísica, e o mais implacável defensor do classicismo, em matéria de arte -, segundo quem $(1974$, §32) o juízo de gosto, porque não se define por conceitos e prescrições universais e necessários, é o que mais necessita do exemplo daquilo que, no desenvolvimento da civilização, tem recebido mais longo assentimento. $\mathrm{Ou}$, em outras palavras, sejam 
tempos de abundância ou de penúria, os clássicos são sempre os clássicos - e ajudam a discernir o que presta do que não presta.

Enfim: adaptando para a poética comparada um famoso par de conceitos nascidos e criados no seio da filologia - refirome aos de história externa e história interna de uma língua qualquer -, isso é tudo o que eu gostaria de dizer sobre a história externa dos experimentos métricos de Horácio, e sua relação com os de Voss, Hill, e também de alguns brasileiros. Sendo assim, resta-me, então, falar um pouco de sua história interna, em que é preciso entrar na minúcia e como que na filigrana da composição - para o que, neste caso, com o fito de exemplificar a poética brasileira de tendência classicizante, permito-me utilizar minhas próprias traduções dos poemas que vamos ler.

1) Comecemos com um fragmento de Alceu e sua tradução, recriação ou imitação horaciana, ambos acompanhados de traduções portuguesas que tanto quanto possível buscam reproduzir o original (no grego e no latim, as longas estão em negrito; no vernáculo - como também em inglês, conforme se verá -, em negrito estão as tônicas e algumas subtônicas, e em itálico, as sílabas acentuadas pela posição ou, na terminologia de García Calvo [2006], pelo engaste rítmico em que se encontram; tanto lá como cá, as sinalefas, elisões e sinéreses vêm sublinhadas).

\begin{tabular}{|c|c|}
\hline Alceu, Fragmento 338 (ed. Campbell, 1982) & Alceu, Fragmento 338 (trad. Nogueira, 2015) \\
\hline 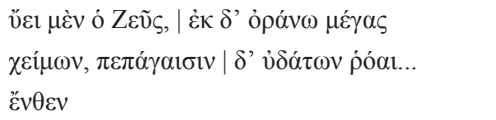 & $\begin{array}{l}\text { Dilúvio de Zeus } \mid \text { - o éter imensamente } \\
\text { desaba, e as correntes } \mid \text { se congestionaram } \\
\text { donde }\end{array}$ \\
\hline 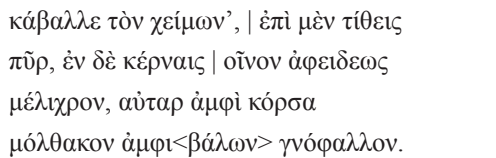 & $\begin{array}{l}\text { Desaba? - dá de ombros, | e repõe então } \\
\text { o fogo e a granel | vinho na copa, amigo, } \\
\text { melífluo: e à roda já das têmporas } \\
\text { mole uma fita ao redor amarra. }\end{array}$ \\
\hline
\end{tabular}




\begin{tabular}{|c|c|}
\hline Horácio, Ode I 9 (ed. Klingner, 1959) & Horácio, Ode I 9 (trad. Nogueira, 2015) \\
\hline Vides ut alta $\mid$ stet niue candidum & Percebes a ne|ve alta que está no branco \\
\hline Soracte nec iam | sustineant onus & Soracte? que não | mais lhe sustêm o fardo \\
\hline siluae laborantes geluque & os bosques a tremer? que o gelo \\
\hline flumina constiterint acuto? & congestionou, afiado, os rios? \\
\hline dissolue frigus | ligna super foco & Derrete esse frio, | vai, e de lenha o fogo \\
\hline large reponens $\mid$ atque benignius & entulha ao repor - mas na amizade agora \\
\hline deprome quadrimum Sabina, & espreme o quadrienal sabino, \\
\hline o Thaliarche, merum diota. & ó Taliarco, licor da bota. \\
\hline permitte diuis | cetera, qui simul & Remete o restan|te aos supernais: tão logo \\
\hline strauere uentos | aequore feruido & no pego os tufões | brabo turbilhonantes \\
\hline deproeliantis, nec cupressi & abatam, nem cipreste nem tam- \\
\hline nec ueteres agitantur orni. & -pouco se agita o vetusto freixo. \\
\hline quid sit futurum | cras fuge quaerere et & O que é do amanhã? | Ah, não perguntes, mas \\
\hline quem Fors dierum | cumque dabit lucro & os dias que $t e \mid$ der a Fortuna põe \\
\hline adpone, nec dulcis amores & no lucro e os (sabem a mel) amores \\
\hline sperne puer neque tu choreas, & nunca desprezes, rapaz, $\underline{\text { e os }}$ coros, \\
\hline donec uirenti $\mid$ canities abest & enquanto é da co|ma inda distante a lenta \\
\hline morosa. nunc et $\mid$ Campus et areae & canície. Eia, pois: | Campo e igualmente praças \\
\hline lenesque sub noctem susurri & e leves sob o breu sussurros \\
\hline composita repetantur hora, & mais uma vez na marcada hora; \\
\hline nunc et latentis | proditor intumo & pois eia: e da esqui|va índice $-\mathrm{o}$ riso grato - \\
\hline gratus puellae $\mid$ risus ab angulo & mocinha de lá | da última das vielas \\
\hline pignusque dereptum lacertis & e algum penhor roubado ao pulso \\
\hline aut digito male pertinaci. & ou a um seu dedo que mal resiste. \\
\hline
\end{tabular}

\section{Comentários}

(a) Em grego e em latim, observo a possibilidade de não coincidência entre o acento natural da palavra e o acento rítmico do verso nas duas primeiras sedes do hendecassílabo - como em v̌ct (1) e uides (1) - e do

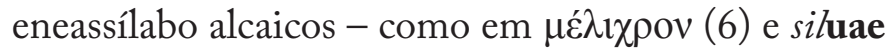
(3); e, em latim, a absoluta regularidade da cesura na quinta sede, em comparação com a oscilação entre a quinta e a sexta, no hendecassílabo grego. 
(b) Em português, noto a dificuldade de reproduzir as três longas consecutivas na quarta, quinta e sexta sedes do hendecassílabo; a opção por ressaltar a regularização da cesura na quinta sede desse verso mediante uma tônica portuguesa; e, atendendo ao que ensina de Mattoso Câmara (1985) em pioneiro e autorizado estudo - a saber, que nossas sílabas postônicas têm força expiratória tendente a zero e assim pouco ou nada influenciam as sílabas precedentes -, bem como à difusa prática da recitação escolar de poesia antiga - que marca o último acento rítmico, não a última longa -, a possibilidade de fins de verso indiferentemente agudos, graves ou esdrúxulos, desde que a última tônica vernácula coincida com o último acento rítmico (não com a última sílaba) do latim ou do grego, de que, pois, legitimamente o português se exime de reproduzir todas as sílabas de um verso.

2) Leiamos e comentemos agora a cuidada tradução alemã de Johann Heinrich Voss dessa mesma ode:

\begin{tabular}{|c|c|}
\hline HorÁcio, Ode I 9 & Horácıo, Ode I 9 (trad. Voss, 1806) \\
\hline Vides ut alta $\mid$ stet niue candidum & Du siehst, wie glanzhell | steht in getürmtem Schnee \\
\hline Soracte nec iam | sustineant onus & Sorakte, kaum noch | unter der Flockenlast \\
\hline siluae laborantes geluque & Der Wald sich aufringt, und von scharfer \\
\hline flumina constiterint acuto? & Kälte der laufende Bach erharscht ist. \\
\hline dissolue frigus | ligna super foco & Den Frost zu lindern, | häufe Gehölz dem Herd \\
\hline large reponens | atque benignius & In reicher Stapel; | und, Thaliarchus, mild \\
\hline deprome quadrimum Sabina, & Gewähr' uns dein vierjährig Labsal \\
\hline o Thaliarche, merum diota. & Aus dem sabinischen Henkelweinkrug! \\
\hline permitte diuis | cetera, qui simul & Das andre lass du | Himmlischen! denn sobald \\
\hline strauere uentos $\mid$ aequore feruido & Ihr Wink die Sturmwind'| auf dem zerwühlten Meer \\
\hline deproeliantis, nec cupressi & Gehemmt vom Ansturz, ruhn Cypressen, \\
\hline nec ueteres agitantur orni. & Ruhn ungeregt die bejahrten Ornen. \\
\hline
\end{tabular}




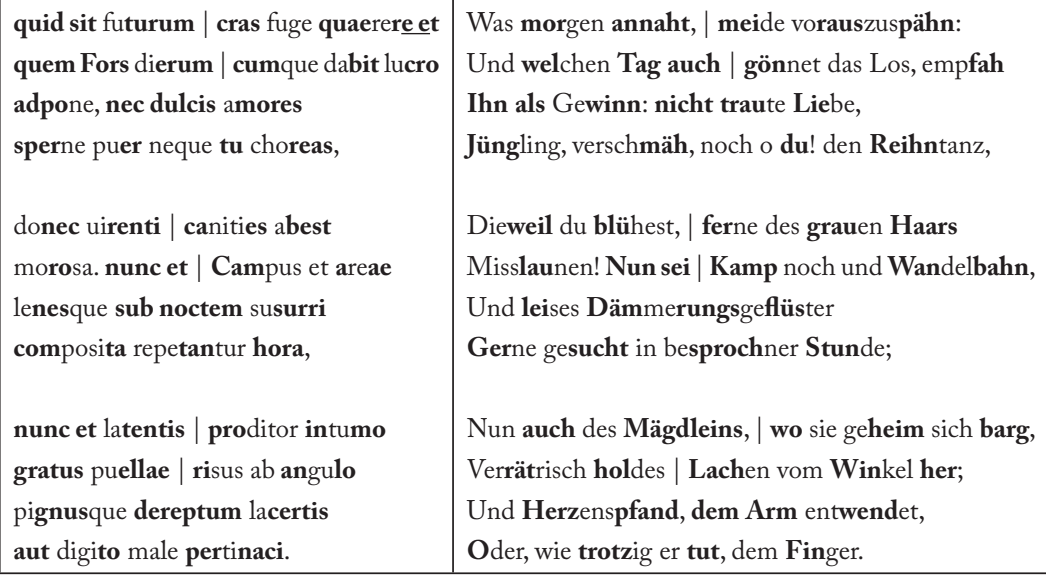

\section{Comentários}

(a) Observe-se a frequência com que o alemão - ou a perícia de Voss no trato com o alemão - consegue reproduzir as três longas consecutivas na quarta, quinta e sexta sedes do hendecassílabo alcaico mediante três tônicas alemãs. A despeito do espinhoso problema do espondeu, nessa língua - Klopstock (1989) costumava lastimar sua escassez (reclamava de barriga cheia) enquanto Voss $\left(1831^{2}\right)$ distinguia-lhe dois tipos -, o facto é que, segundo o primeiro, palavras e sílabas alemãs são longas quando exprimem ideias primárias [como em "Sturmwind"], e quando exprimem ideias secundárias [como a desinência do nominativo em "holdes", que, sem embargo, tratando-se de sílaba fechada, Voss considerava longa] são curtas.

3) Finalmente, um trechinho de uma ode sáfica de Horácio (IV 2) - só pra observarmos-lhe os principais característicos métrico-rítmicos - seguida de poema simplesmente magistral de Geoffrey Hill no mesmo metro (ambos acompanhados de traduções), com que me despeço e concluo. 


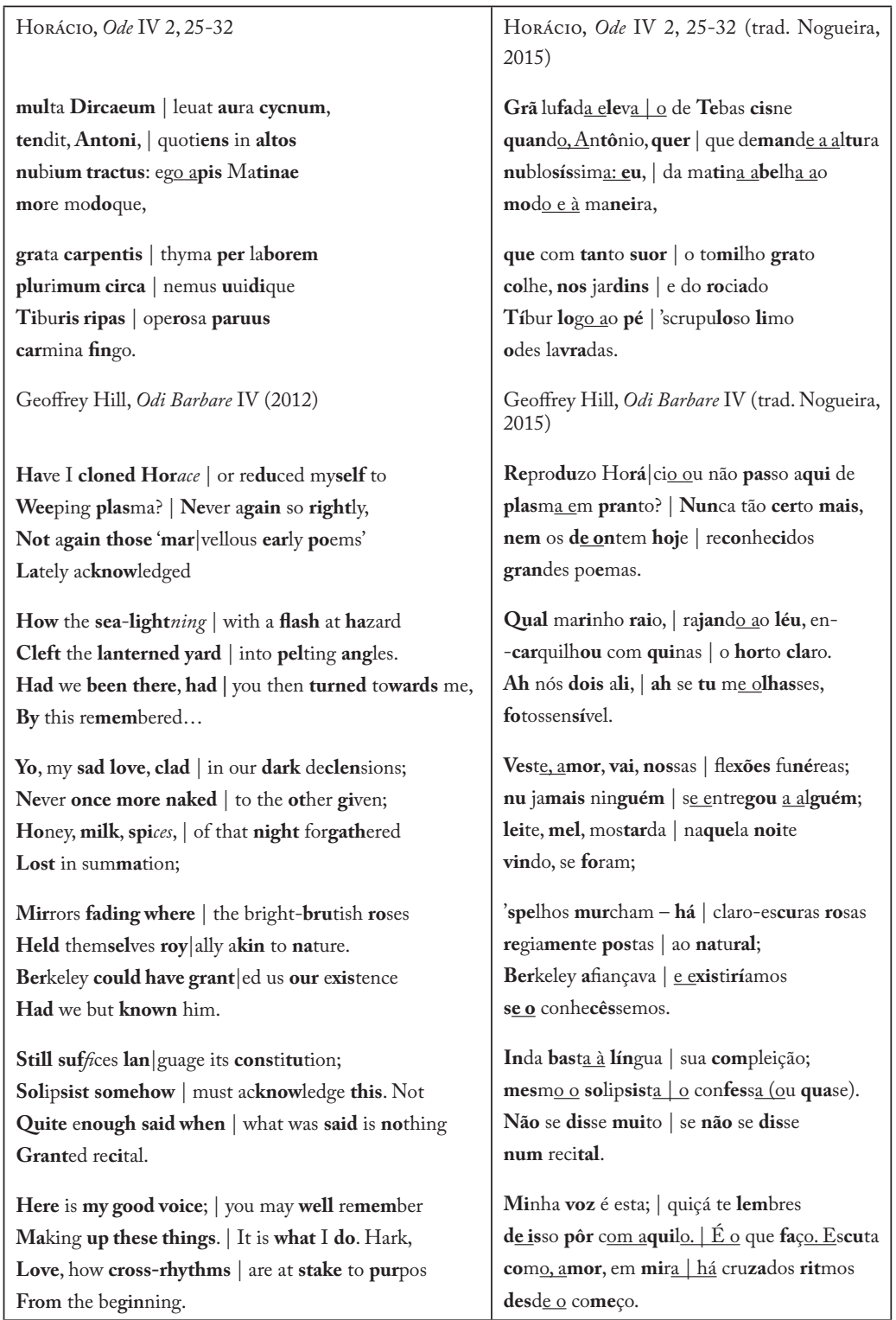

\section{Comentários}

(a) Em latim, embora o trecho escolhido o não patenteie, o hendecassílabo sáfico admite cesura na sexta sede, 
que, não obstante, é muito mais rara que a cesura na quinta.

(b) Em português, ressalto a dificuldade de reproduzir as três longas consecutivas na terceira, quarta e quinta sedes do hendecassílabo sáfico.

(c) Em inglês, valendo-se do que Gerard Manley Hopkins (2003) chamou sprung rhythm, Hill é amiúde bem-sucedido em reproduzir as já mencionas três longas em série mediante três tônicas inglesas.

É isso ${ }^{10}$.

\section{Bibliografia}

Antunes, C.L. B. 2012. "Métrica e Rítmica nas Odes Píticas de Píndaro". Tese de Doutoramento. São Paulo: Universidade de São Paulo.

Câmara Jr. J. M. 1985. História e Estrutura da Lingua Portuguesa. Rio de Janeiro: Padrão.

Campbell, D. A. (ed.) 1982. Greek Lyric. Sappho. Alcaeus. CambridgeMA / London: Loeb.

Campos, H. 19924. Metalinguagem E Outras Metas. São Paulo: Perspectiva.

Eliot, T. S. 1921. The Sacred Wood: Essays on Poetry and Criticism. New York: Alfred A. Knopf.

Even-Zohar, I. 1990. “The 'Literary System”. In: Polysystem Studies: 27-44.

Filho, J. 2014. A Dimensão Necessária. Ilhéus: Mondrongo.

Flores, G. G. 2014. "Uma Poesia de Mosaicos nas Odes de Horácio: Comentário e Tradução Poética”. Tese de Doutoramento. São Paulo: Universidade de São Paulo.

10 Gostaria de registrar o meu agradecimento ao crítico e tradutor britânico Chris Miller - tradutor inclusive do português, observe-se - pelo prestimoso auxílio que me ofereceu na tradução do poema de Hill. 
García Calvo, A. 2006. Tratado de Rítmica y Prosodia y de Métrica y Versificación. Zamora: Lucina.

Hill, G. 2012. Odi Barbare. Thame: Clutag.

Hopkins, G. M. 2003. Major Poems and Sipiritual Writings. New York: Vintage Spiritual Classics.

Kant, I. 1974. Kritik der Urteilskraft. Frankfurt: Suhrkamp. . 1784. "Beantwortung der Frage: Was ist Aufklärung?" In: Berlinische Monatsschrift 12: 481-494.

Kenner, H. 1988. A Sinking Island: The Modern English Writers. New York: A. Knopf.

Klingner, F. (ed.) 1959. Quintus Horatius Flaccus: Opera. Leipzig: Teubner.

Klopstock, F. G. 1989. Gedanken über die Natur der Poesie. Frankfurt: Insel.

Larkin, P. 1983. "The Pleasure Principle". In: Required Writing: Miscellaneous Pieces 1955-1982. London: Faber and Faber.

Nogueira, É. 2014. Poesia Bovina. São Paulo: É Realizações. . 2012. Verdade, Contenda e Poesia nos Idílios de Teócrito. São Paulo: Humanitas.

Oliva Neto. J. A. 2013. "Dos Gêneros da Poesia Antiga e sua Tradução em Poetuguês”. Tese de Livre-Docência. São Paulo: Universidade de São Paulo.

Oliva Neto,J.A. \& Nogueira,É.2013. “O Hexâmetro Dactílico Vernáculo antes de Carlos Alberto Nunes”. Scientia Traductionis 13: 295-311.

Rosado Fernandes, R.M. (ed.) 1986. Dionísio de Halicarnasso: Tratado da Imitação. Lisboa: Instituto Nacional de Investigação Científica.

Veyne, P. 1971. Comment on écrit l'histoire. Paris: Éditions du Seuil.

Voss, J. H. 18312. Zeitmessung der deutschen Sprache. Königsberg: Universitäts-Buchhandlung. 18223. Des Quintus Horatius Flaccus Werke. 2 Bänden. Braunschweig: F. Vieweg. 